\section{Kidney \\ Blood Pressure Research}

\title{
Association of $-1082 A>G$ Polymorphism in the Interleukin-10 Gene with Estimated Glomerular Filtration Rate in Type 2 Diabetes
}

\author{
Evelise Regina Polina ${ }^{a} \quad$ Bruna Letícia da Silva Pereira ${ }^{a}$ Daisy Crispim ${ }^{b}$ \\ Renan Cesar Sbruzzi ${ }^{a}$ Luis Henrique Canani ${ }^{b}$ Kátia Gonçalves dos Santos ${ }^{a, c}$ \\ aLaboratory of Human Molecular Genetics, Universidade Luterana do Brasil (ULBRA), Canoas,

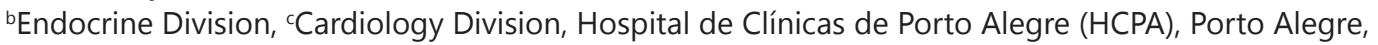 \\ Brazil
}

\section{Key Words}

Type 2 diabetes • Diabetic kidney disease $•$ EGFR • Interleukin-10 • Polymorphism

\begin{abstract}
Background/Aims: The $-1082 \mathrm{~A}>\mathrm{G}$ polymorphism (rs1800896) in the interleukin-10 (IL10) gene has been associated with type 2 diabetes and diabetic retinopathy, but its relationship with diabetic kidney disease (DKD) is uncertain. The aim of this case-control study was to investigate whether the $-1082 \mathrm{~A}>\mathrm{G}$ polymorphism is associated with DKD in white Brazilians with type 2 diabetes mellitus. Methods: Genotyping was done by real-time polymerase chain reaction for 597 type 2 diabetic outpatients. The definition of DKD was based on estimated glomerular filtration rate (eGFR) and albuminuria, and the patients were grouped in three categories: no DKD ( $n=249)$, mild to moderate DKD $(n=222)$, and severe DKD $(n=126)$. Results: The frequency of the minor $(G)$ allele in subjects without DKD did not differ from that observed in subjects with DKD (0.35 vs 0.39 , respectively; $P=0.192)$. Genotype frequencies in subjects without DKD were not significantly different from those observed among patients with mild to moderate DKD or severe DKD. However, considering only the eGFR categories as an indicator of renal function, the AG genotype was independently associated with an increased risk of mildly to moderately decreased eGFR (G3a category) and GG genotype was independently associated with increased risk of kidney failure (G5 category) as compared with AA genotype. Conclusion: Our findings support the hypothesis that the $-1082 \mathrm{~A}>\mathrm{G}$ polymorphism in the ILIO gene might be associated with DKD in white Brazilians with type 2 diabetes.
\end{abstract}




\section{Kidney Blood Pressure Research}

Polina et al.: Association Between -1082A>G Polymorphism and Egfr

\section{Introduction}

Diabetic kidney disease (DKD) is a syndrome characterized by structural and functional changes with reduced estimated glomerular filtration rate (eGFR) and/or albuminuria. It occurs in $10-40 \%$ of type 2 diabetic patients and is the leading cause of end-stage renal disease (ESRD) [1]. Besides ESRD, lower GFR and higher levels of albuminuria are independently associated with acute kidney injury, cardiovascular mortality, and all-cause mortality [2, 3]. Longer duration of diabetes, poor glycemic control, and hypertension are the most common risk factors for DKD and its progression. Even so, the prevalence of DKD varies with ethnicity and individual risk of DKD is influenced by genetic predisposition $[4,5]$.

The early phase of DKD is characterized by glomerular hyperfiltration, followed by progressive morphological and ultrastructural changes, including the mesangial expansion, thickening of the basement membrane, nodular glomerulosclerosis, and loss of podocytes [1]. Such changes are promoted in the diabetic milieu, as hemodynamic alterations, metabolic derangements, and endothelial dysfunction trigger cell signaling cascades that lead renal cells to produce chemokines, growth factors, adhesion molecules, and inflammatory cytokines. This, in turn, results in the recruitment, differentiation, proliferation, activation, and infiltration of monocytes/macrophages and T lymphocytes into the kidney, contributing to a cycle of inflammation, oxidative stress, cellular injury, progressive fibrosis, and loss of GFR $[1,6,7]$.

Inflammation has been increasingly recognized as having a central role in the onset and progression of DKD. Circulating levels of proinflammatory cytokines are increased in diabetic patients and correlate with progressive albuminuria [7]. Interleukin-10 (IL-10) is a multifunctional cytokine that exerts predominantly anti-inflammatory effects by inhibiting the production of proinflammatory cytokines, antigen presentation, and proliferation of $\mathrm{T}$ cells. Depending on the circumstances and the cell type, IL-10 may exert immunostimulatory effects by upregulating MHC class II expression on B lymphocytes. IL-10 is expressed by most immune cells, but is not restricted to them $[8,9]$. Chen et al $[6]$. demonstrated that kidney tissue isolated from diabetic patients express more IL-10 than the kidney tissue isolated from non-diabetic subjects. In type 2 diabetic Chinese patients, serum levels of IL-10 were increased in those with macroalbuminuria and positively related to the urinary albuminto-creatinine ratio (UACR) [10]. In contrast, urinary IL-10 concentration was inversely correlated with UACR in normoalbuminuric Brazilians with type 2 diabetes [11].

The levels of IL-10 are highly variable in healthy individuals $[12,13]$ and are regulated by functional variants in the gene encoding IL-10 (IL10), such as the $-1082 \mathrm{~A}>\mathrm{G}$ ( $\mathrm{rs} 1800896)$ polymorphism in the promoter region [13]. This polymorphism has been reported to be associated with type 2 diabetes [14], renovascular disease [15], and clinical outcomes in endstage renal disease [16]. We recently showed that the $-1082 \mathrm{~A}>\mathrm{G}$ polymorphism is associated with diabetic retinopathy in type 2 diabetic patients (unpublished data). Previous studies that evaluated the relationship between this polymorphism and kidney disease in diabetic patients have obtained conflicting results [17-22]. Therefore, we aimed to investigate whether the $-1082 \mathrm{~A}>\mathrm{G}$ polymorphism (rs1800896) in the IL10 gene is associated with diabetic kidney disease in white Brazilians with type 2 diabetes mellitus.

\section{Materials and Methods}

\section{Subjects}

This case-control study was carried out with 597 subjects with type 2 diabetes who regularly attend the endocrinology outpatient clinics of four public hospitals in Rio Grande do Sul State, in Southern Brazil (Hospital de Clínicas de Porto Alegre, Hospital Nossa Senhora da Conceição, Hospital São Vicente de Paulo, and Fundação Universitária de Rio Grande). Five hundred and forty-seven patients were enrolled between 2000 and 2010, and 50 patients were included in the study in 2015 or 2016. Type 2 diabetes was defined 


\section{Kidney Blood Pressure Research}

according to the guidelines of the American Diabetes Association [23], and the inclusion criteria were age $\geq 30$ years at the diagnosis of diabetes, no need of permanent insulin treatment within the first year of diagnosis, and no previous episodes of ketoacidosis. Moreover, all patients classified as having no kidney disease had to have diabetes for at least 5 years to be included in the study. No other inclusion or exclusion criteria were used. All subjects were self-declared white Brazilians of European (Caucasian) ancestry, mainly from Portugal, Spain, Italy, and Germany. The study was approved by the hospital ethics committees and all patients participating in this study provided written informed consent.

\section{Clinical and laboratory evaluation}

All patients underwent a comprehensible physical and laboratory evaluation, as previously described in detail [24, 25]. A questionnaire was used to collect data about their medical history, such as the age at diabetes diagnosis, smoking history, and use of medication. Diabetic retinopathy was evaluated by direct fundoscopy under mydriasis, and fluorescein angiography was done when indicated. The diagnosis of DKD was based on estimated glomerular filtration rate (eGFR) and albuminuria according to the KDIGO 2012 classification [2]. Serum creatinine was measured by the Jaffé reaction, and albuminuria was measured by immunoturbidimetry [24] in the absence of conditions that could interfere with albumin measurement, such as fever and urinary tract infection. GFR was estimated using the CKD-EPI formula [26], and albuminuria was based on at least two of three consecutive timed urine collections $(\mu \mathrm{g} / \mathrm{min})$ or random spot urine samples (mg/L) for $64 \%$ and $36 \%$ of the patients, respectively. Patients were then grouped in three categories: no kidney disease, mild to moderate kidney disease, and severe kidney disease (Table 1).

In relation to macrovascular disease, most patients were clinically evaluated for the presence of ischemic heart disease $(n=451)$, peripheral vascular disease $(n=451)$, and stroke $(n=416)$. Ischemic heart disease was defined in the presence of angina or possible infarct according to the World Health Organization (WHO) Cardiovascular Questionnaire and/or the presence of resting electrocardiogram abnormalities and/ or the presence of perfusion abnormalities on myocardial scintigraphy. Peripheral vascular disease was diagnosed by the presence of intermittent claudication according to the World Health Organization (WHO) Cardiovascular Questionnaire and/or the absence of foot pulses. Stroke, which was identified by previous history and/or the presence of sequels, was not evaluated in the endocrinology outpatient clinics of Hospital Nossa Senhora da Conceição.

Table 1. Prognosis of chronic kidney disease by GFR and albuminuria categories: KDIGO 2012. Modified from Inker et al. [2]. Abbreviations: DKD = diabetic kidney disease; GFR = glomerular filtration rate

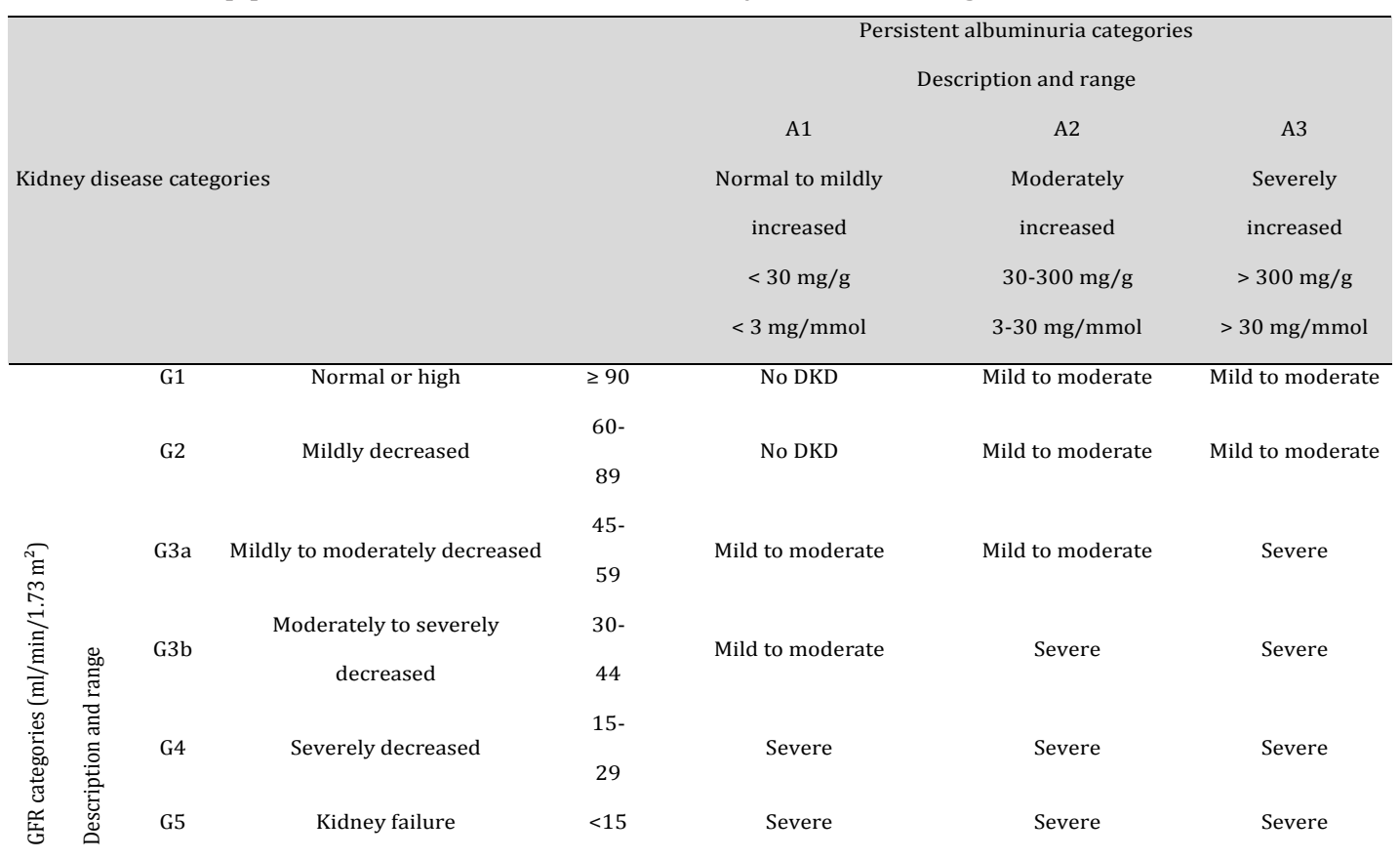




\section{Kidney Blood Pressure Research}

Kidney Blood Press Res 2017;42:1164-1174

\begin{tabular}{|l|l|}
\hline DOI: 10.1159/000485863 & (C) 2017 The Author(s). Published by S. Karger AG, Basel
\end{tabular}

Published online: December 11, 2017 www.karger.com/kbr

Polina et al.: Association Between -1082A>G Polymorphism and Egfr

\section{Genotyping}

Genomic DNA was isolated from peripheral blood leukocytes by the salting out method, as described by Lahiri and Nurnberger Jr [27]. The $-1082 \mathrm{~A}>\mathrm{G}$ polymorphism in the IL10 gene was genotyped by realtime polymerase chain reaction (PCR) using proprietary primers and probes (TaqMan ${ }^{\circledR}$ Genotyping Assay, assay ID: C_1747360_10; Thermo Fisher Scientific, Waltham, USA). Amplification reactions were done in optical tubes, in a $10 \mu \mathrm{L}$ total volume, containing 2 ng of genomic DNA, TaqMan® Genotyping Master Mix 1X, and Genotyping Assay 1X (Thermo Fisher Scientific). Optical tubes were loaded into a real-time PCR thermal cycler and heated for $10 \mathrm{~min}$ at $95^{\circ} \mathrm{C}$, followed by 40 cycles of $95^{\circ} \mathrm{C}$ for $15 \mathrm{~s}$, and $60^{\circ} \mathrm{C}$ for $1 \mathrm{~min}$. Files with the fluorescence data collected during the amplification runs were analyzed with the StepOne software version 2.3 (Thermo Fisher Scientific). Samples with known genotypes were used in each run and the investigator who performed the genotyping was blinded to the patients' renal status, clinical condition, and laboratory data. To ensure the accuracy of the genotyping results, genotypes were determined independently by two investigators, and ambiguous samples were re-genotyped or discarded.

\section{Statistical analysis}

Demographic, clinical, laboratory, and genetic data are expressed as means \pm standard deviation (SD), medians $\left(25^{\text {th }}-75^{\text {th }}\right.$ percentiles), absolute frequencies (percentages), or relative frequencies. The normality of continuous variables was verified using the Shapiro-Wilk test. Continuous data were compared between groups by ANOVA or Kruskal-Wallis tests, followed by the Tukey or Dunn post-hoc tests, as appropriate. The chi-square test was used to compare the categorical variables, including the genotype and allele frequencies, between groups. The Yates correction was applied for the comparisons involving $2 \times 2$ contingency tables, and $P$ values computed for the analysis of contingency tables larger than $2 \times 2$ were corrected for multiple pairwise comparisons with the Bonferroni formula. The chi-square test was also used to test for HardyWeinberg equilibrium. Logistic regression analysis was done to test for association of the $-1082 \mathrm{~A}>\mathrm{G}$ polymorphism with DKD, adjusting for the covariates that were also associated with it in the univariate analyses. Statistical analyses were done using SPSS (version 18.0; SPSS Inc., Chicago, USA) and WinPEPI (version 11.43) [28] statistical softwares. A two-tailed $P$ value $<0.05$ was considered statistically significant.

\section{Results}

\section{Characteristics of the patients according to the renal status}

Based on the levels of eGFR and albuminuria, this study involved 249 patients without DKD and 348 patients with some degree of DKD. Briefly, patients with severe DKD were more often male, had diabetes for longer, higher prevalence of insulin therapy, hypertension, diabetic retinopathy, ischemic heart disease, peripheral vascular disease, and stroke than patients without DKD. They were also leaner, had higher levels of systolic blood pressure, serum creatinine, urinary albumin excretion rate, eGFR, and had lower levels of glycated hemoglobin and HDL cholesterol as compared with patients without DKD (Table 2).

Overall, in the population studied the frequencies of the AA, AG, and GG genotypes were $37.5 \%, 49.8 \%$, and $12.7 \%$, respectively. The frequency of the minor $(G)$ allele was $37.6 \%$. As shown in Table 2, the genotype and allele frequencies in patients without DKD were not significantly different from those observed in patients with mild/moderate or severe DKD. Genotype frequencies of the $-1082 \mathrm{~A}>\mathrm{G}$ polymorphism did not deviate from those predicted by Hardy-Weinberg equilibrium in all groups of subjects.

\section{Characteristics of the patients according to the $-1082 A>$ G polymorphism}

Demographic and clinical profile of patients with different genotypes of $-1082 \mathrm{~A}>\mathrm{G}$ polymorphism was similar for most characteristics (Table 3). However, subjects with the AA genotype had higher glycated hemoglobin levels than those with AG genotype, whereas patients with GG genotype were more often taking beta-blockers as compared with those with other genotypes. Although it did not reach statistical significance, subjects with GG 


\section{Kidney \\ Blood Pressure Research}

Table 2. Characteristics of type 2 diabetic patients according to renal status. Data are expressed as mean \pm $\mathrm{SD}$, median $\left(25^{\text {th }}-75^{\text {th }}\right.$ percentiles $)$, percentage, or relative frequency. P values were obtained by chi-square or Kruskal-Wallis tests. Means, medians, or percentages indicated with different letters were significantly different in the pairwise comparisons after adjustment for multiple comparisons ( $\mathrm{P}<0.05)$. *Data available for 451 patients. ${ }^{\dagger}$ Data available for 416 patients. Abbreviations: ACE = angiotensin-converting enzyme; eGFR = estimated glomerular filtration rate

\begin{tabular}{|c|c|c|c|c|}
\hline & & Kidne & & \\
\hline & No $(\mathrm{n}=249)$ & Mild/moderate $(n=222)$ & Severe $(n=126)$ & $\mathrm{P}$ \\
\hline Sex (male \%) & $38.2^{\mathrm{a}}$ & $47.3^{\mathrm{a}, \mathrm{b}}$ & $57.1^{\mathrm{b}}$ & 0.002 \\
\hline Age (years) & $60.4 \pm 9.1$ & $60.6 \pm 10.4$ & $62.7 \pm 9.4$ & 0.125 \\
\hline Duration of diabetes (years) & $13.7 \pm 6.7 \mathrm{a}$ & $12.9 \pm 8.5^{\mathrm{a}}$ & $17.2 \pm 9.1^{\mathrm{b}}$ & $<0.001$ \\
\hline Glycated hemoglobin (\%) & $7.1 \pm 1.9^{a}$ & $7.3 \pm 2.2^{\mathrm{a}}$ & $6.3 \pm 1.8^{\mathrm{b}}$ & 0.002 \\
\hline Insulin use (\%) & $35.7^{\mathrm{a}}$ & $42.3^{\mathrm{a}}$ & $63.5^{\mathrm{b}}$ & $<0.001$ \\
\hline Body mass index $\left(\mathrm{kg} / \mathrm{m}^{2}\right)$ & $29.1 \pm 5.2^{\mathrm{a}}$ & $29.6 \pm 5.3^{a}$ & $27.4 \pm 4.7^{\mathrm{b}}$ & 0.008 \\
\hline Hypertension (\%) & $70.7 \mathrm{a}$ & $77.5^{\mathrm{a}, \mathrm{b}}$ & $83.3^{\mathrm{b}}$ & 0.020 \\
\hline Systolic blood pressure (mmHg) & $142 \pm 23^{a}$ & $147 \pm 26^{a, b}$ & $150 \pm 25^{b}$ & 0.011 \\
\hline Diastolic blood pressure $(\mathrm{mmHg})$ & $86 \pm 13$ & $87 \pm 15$ & $84 \pm 12$ & 0.200 \\
\hline Antihypertensive medication & & & & \\
\hline ACE inhibitor (\%) & $36.9^{\mathrm{a}}$ & $50.0^{\mathrm{b}}$ & $42.1^{\mathrm{a}, \mathrm{b}}$ & 0.017 \\
\hline Beta-blocker (\%) & 26.5 & 32.0 & 36.5 & 0.121 \\
\hline Total cholesterol $(\mathrm{mmol} / \mathrm{L})$ & $5.3 \pm 1.1^{\mathrm{a}, \mathrm{b}}$ & $5.4 \pm 1.5^{a}$ & $4.9 \pm 1.4 \mathrm{~b}$ & 0.025 \\
\hline HDL cholesterol $(\mathrm{mmol} / \mathrm{L})$ & $1.2 \pm 0.9 \mathrm{a}$ & $1.1 \pm 0.3^{\mathrm{b}}$ & $1.1 \pm 0.4 \mathrm{~b}$ & $<0.001$ \\
\hline Triglycerides (mmol/L) & $1.7(1.2-2.3)$ & $1.9(1.3-3.0)$ & $1.9(1.4-2.9)$ & 0.025 \\
\hline Serum creatinine $(\mu \mathrm{mol} / \mathrm{L})$ & $62(52-73)^{a}$ & $71(54-84)^{\mathrm{b}}$ & $380(177-673)^{c}$ & $<0.001$ \\
\hline Urinary albumin excretion rate & & & & \\
\hline Timed collection $(\mu \mathrm{g} / \mathrm{min})$ & $5.0(3.4-8.6)^{\mathrm{a}}$ & $68.8(31.7-216.2)^{\mathrm{b}}$ & $456.0(325.4-963.0)^{\mathrm{b}}$ & $<0.001$ \\
\hline Random spot collection $(\mathrm{mg} / \mathrm{L})$ & $3.0(1.0-5.0)^{\mathrm{a}}$ & $57.0(23.5-223.7)^{\mathrm{b}}$ & $1,088.0(355.4-1,974.2)^{\mathrm{c}}$ & $<0.001$ \\
\hline $\mathrm{eGFR}\left(\mathrm{mL} / \mathrm{min} / 1.73 \mathrm{~m}^{2}\right)$ & $97(87-106)^{a}$ & $91(71-104)^{\mathrm{b}}$ & $14(6-29)^{c}$ & $<0.001$ \\
\hline Diabetic retinopathy (\%) & $40.6^{\mathrm{a}}$ & $48.6^{\mathrm{a}}$ & $77.0^{\mathrm{b}}$ & $<0.001$ \\
\hline Ischemic heart disease (\%)* & $33.9^{\mathrm{a}}$ & $32.0^{\mathrm{a}}$ & $56.3^{\mathrm{b}}$ & $<0.001$ \\
\hline Peripheral vascular disease (\%)* & $23.4^{\mathrm{a}}$ & $32.5^{\mathrm{a}}$ & $53.4^{\mathrm{b}}$ & $<0.001$ \\
\hline Previous stroke $(\%)^{\dagger}$ & $3.7 \mathrm{a}$ & $8.3^{\mathrm{a}, \mathrm{b}}$ & $12.1^{\mathrm{b}}$ & 0.030 \\
\hline IL-10 $-1082 \mathrm{~A}>\mathrm{G}$ polymorphism & & & & \\
\hline AA/AG/GG genotypes (\%) & $40.6 / 48.2 / 11.2$ & $36.0 / 50.5 / 13.5$ & $34.1 / 51.6 / 14.3$ & 0.710 \\
\hline $\mathrm{A} / \mathrm{G}$ alleles & $0.65 / 0.35$ & $0.61 / 0.39$ & $0.60 / 0.40$ & 0.370 \\
\hline
\end{tabular}

Table 3. Characteristics of type 2 diabetic patients according to $-1082 \mathrm{~A}>\mathrm{G}$ genotypes. Data are expressed as mean $\pm \mathrm{SD}$, median $\left(25^{\text {th }}-75^{\text {th }}\right.$ percentiles $)$, or percentage. P values were obtained by chi-square, ANOVA, or Kruskal-Wallis tests. Means and percentages indicated with different letters were significantly different in the pairwise comparisons after adjustment for multiple comparisons ( $\mathrm{P}<0.05$ ). *Data available for 451 patients. ${ }^{\dagger}$ Data available for 416 patients. Abbreviations: ACE = angiotensin-converting enzyme; eGFR = estimated glomerular filtration rate

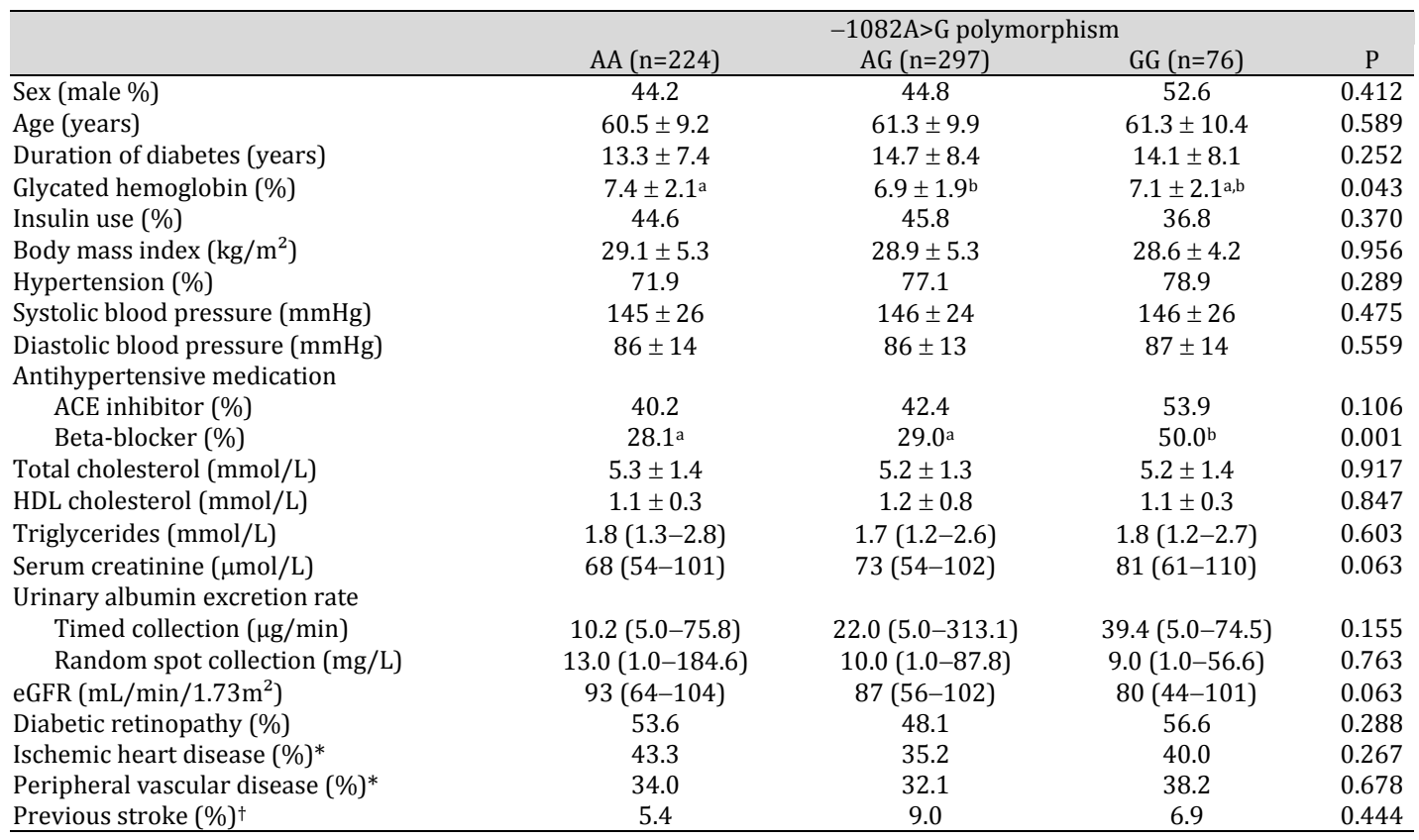




\section{Kidney \\ Blood Pressure Research}

Polina et al.: Association Between -1082A>G Polymorphism and Egfr

genotype seemed to have higher serum creatinine levels and lower eGFR compared to those with AG and AA genotypes (Table 3). Then, we decided to assess the relationship between the $-1082 \mathrm{~A}>\mathrm{G}$ polymorphism and $\mathrm{DKD}$, as defined by eGFR categories.

\section{Association between the $-1082 A>G$ polymorphism and eGFR categories}

Considering the six categories of DKD defined according to the eGFR values, we observed an increased frequency of $\mathrm{AG}$ and GG genotypes in patients with mildly to moderately decreased eGFR (G3a) and in those with kidney failure (G5), respectively, as compared with patients with normal or high eGFR (G1). Moreover, the G allele was more frequent in subjects with kidney failure (G5) than in those with normal or high eGFR (G1) (Table 4). However, these statistical differences were lost after correction for multiple pairwise comparisons.

Next, we tested the association of the $-1082 \mathrm{~A}>\mathrm{G}$ polymorphism with mildly to moderately decreased eGFR (G3a) and kidney failure (G5), using four genetic models (codominant, dominant, recessive, and overdominant) and assuming the $\mathrm{G}$ allele as the risk allele. In relation to mildly to moderately decreased eGFR (G3a), the G allele was associated with increased risk of DKD under the dominant and codominant models, even after adjusting for the covariates that were also associated with this outcome in the univariate analyses (Table 5). Similarly, the G allele was associated with increased risk of kidney failure under the dominant, recessive, and codominant models after adjusting for the covariates that were also associated with it (Table 6).

\section{Discussion}

In this study, we investigated whether the $-1082 \mathrm{~A}>\mathrm{G}$ polymorphism (rs1800896) in the $I L 10$ gene is associated with the presence or severity of DKD in white type 2 diabetic patients from Southern Brazil. Using both albuminuria and eGFR categories to define DKD, we failed to detect an association with this polymorphism. However, when considering only the eGFR categories, the $G$ allele was independently associated with an increased risk of mildly to moderately decreased eGFR (G3a) and kidney failure (G5). We tested four genetic models and some of them revealed statistically significant associations with eGFR categories G3a and G5. Identifying which model is the correct one is hampered by the small number of subjects in G3a and G5 categories and the low frequency of the GG genotype. This may have led to some false positive associations and the loss of others. Combining the results of

Table 4. Genotype and allele frequencies of $-1082 \mathrm{~A}>\mathrm{G}$ polymorphism according to eGFR categories. Data are expressed as $\mathrm{n}$ (percentage) or relative frequency. $\mathrm{P}$ values were obtained by chi-square. Abbreviation: eGFR = estimated glomerular filtration rate

\begin{tabular}{|c|c|c|c|c|c|c|c|}
\hline & \multicolumn{7}{|c|}{ eGFR classification KDIGO $2012\left(\mathrm{~mL} / \mathrm{min} / 1.73 \mathrm{~m}^{2}\right)$} \\
\hline & $\mathrm{G} 1(\geq 90)$ & G2 (60-89) & G3a (45-59) & G3b (30-44) & G4 (15-29) & G5 $(<15)$ & $\mathrm{P}$ \\
\hline Genotypes & $\mathrm{n}=288$ & $\mathrm{n}=156$ & $\mathrm{n}=36$ & $\mathrm{n}=22$ & $\mathrm{n}=28$ & $\mathrm{n}=67$ & \\
\hline $\mathrm{AA}$ & $118(41.0)$ & $56(35.9)$ & $7(19.4)$ & $9(40.9)$ & $14(50.0)$ & 20 (29.9) & 0.061 \\
\hline $\mathrm{AG}$ & $142(49.3)$ & $76(48.7)$ & $24(66.7)$ & $11(50.0)$ & $12(42.9)$ & $32(47.8)$ & \\
\hline GG & $28(9.7)$ & $24(15.4)$ & 5 (13.9) & $2(9.1)$ & $2(7.1)$ & $15(22.4)$ & \\
\hline \multicolumn{8}{|l|}{ Alleles } \\
\hline A & 0.66 & 0.60 & 0.53 & 0.66 & 0.71 & 0.54 & 0.029 \\
\hline $\mathrm{G}$ & 0.34 & 0.40 & 0.47 & 0.34 & 0.29 & 0.46 & \\
\hline
\end{tabular}




\section{Kidney Blood Pressure Research}

Polina et al.: Association Between -1082A>G Polymorphism and Egfr

Table 5. Association between $-1082 \mathrm{~A}>$ G genotypes and eGFR category G3a. Genotype data are expressed as $\mathrm{n}$ (percentage). * Multiple logistic regression adjusted for age (years), duration of diabetes (years), systolic blood pressure (mmHg), and regular use of insulin (yes/no). Abbreviations: eGFR = estimated glomerular filtration rate; $\mathrm{OR}=$ odds ratio; $95 \% \mathrm{CI}=95 \%$ confidence interval

\begin{tabular}{|c|c|c|c|c|c|c|c|}
\hline \multirow[b]{2}{*}{ Model } & \multicolumn{4}{|c|}{ eGFR category } & \multirow[b]{2}{*}{$P$} & \multirow[b]{2}{*}{ Adjusted OR (95\% CI)* } & \multirow[b]{2}{*}{$\mathrm{P}^{*}$} \\
\hline & Genotype & G1 (n=288) & G3a $(n=36)$ & Unadjusted OR $(95 \% \mathrm{CI})$ & & & \\
\hline \multirow[t]{3}{*}{ Codominant } & AA & $118(41.0)$ & $7(19.4)$ & 1.00 (Reference) & & 1.00 (Reference) & \\
\hline & $\mathrm{AG}$ & $142(49.3)$ & $24(66.7)$ & $2.85(1.19-6.85)$ & 0.019 & $2.71(1.12-6.59)$ & 0.028 \\
\hline & GG & $28(9.7)$ & $5(13.9)$ & $3.01(0.89-10.19)$ & 0.077 & $2.82(0.79-10.01)$ & 0.111 \\
\hline \multirow[t]{2}{*}{ Dominant } & AA & $118(41.0)$ & $7(19.4)$ & 1.00 (Reference) & & 1.00 (Reference) & \\
\hline & $\mathrm{AG}+\mathrm{GG}$ & $170(59.0)$ & $29(80.6)$ & $2.88(1.22-6.78)$ & 0.016 & $2.62(1.02-6.75)$ & 0.045 \\
\hline \multirow[t]{2}{*}{ Recessive } & $\mathrm{AA}+\mathrm{AG}$ & $260(90.3)$ & $31(86.1)$ & 1.00 (Reference) & & 1.00 (Reference) & \\
\hline & GG & $28(9.7)$ & $5(13.9)$ & $1.50(0.54-4.16)$ & 0.438 & $1.55(0.48-5.01)$ & 0.465 \\
\hline \multirow[t]{2}{*}{ Overdominant } & $\mathrm{AA}+\mathrm{GG}$ & $146(50.7)$ & $12(33.3)$ & 1.00 (Reference) & & 1.00 (Reference) & \\
\hline & $\mathrm{AG}$ & $142(49.3)$ & $24(66.7)$ & $2.06(0.99-4.27)$ & 0.053 & $1.90(0.84-4.29)$ & 0.123 \\
\hline
\end{tabular}

Table 6. Association between $-1082 \mathrm{~A}>\mathrm{G}$ genotypes and eGFR category G5. Genotype data are expressed as $\mathrm{n}$ (percentage). ${ }^{*}$ Multiple logistic regression adjusted for male sex, age (years), duration of diabetes (years), hypertension (yes/no), body mass index $\left(\mathrm{kg} / \mathrm{m}^{2}\right.$ ), regular use of insulin (yes/no), HDL cholesterol ( $\mathrm{mmol} / \mathrm{L})$, and retinopathy (yes/no). Abbreviations: eGFR = estimated glomerular filtration rate; $\mathrm{OR}=$ odds ratio; $95 \% \mathrm{CI}=95 \%$ confidence interval

\begin{tabular}{|c|c|c|c|c|c|c|c|}
\hline \multirow[b]{2}{*}{ Model } & \multirow[b]{2}{*}{ Genotype } & \multicolumn{2}{|c|}{ eGFR category } & \multirow[b]{2}{*}{ Unadjusted OR ( $95 \%$ CI) } & \multirow[b]{2}{*}{$P$} & \multirow[b]{2}{*}{ Adjusted OR (95\% CI)* } & \multirow[b]{2}{*}{$\mathrm{P}^{*}$} \\
\hline & & G1 (n=288) & G5 $(n=67)$ & & & & \\
\hline \multirow[t]{3}{*}{ Codominant } & AA & $118(41.0)$ & $20(29.9)$ & 1.00 (Reference) & & 1.00 (Reference) & \\
\hline & AG & $142(49.3)$ & $32(47.7)$ & $1.33(0.72-2.45)$ & 0.360 & $2.41(0.97-6.00)$ & 0.058 \\
\hline & GG & $28(9.7)$ & $15(22.4)$ & $3.16(1.44-6.94)$ & 0.004 & $5.35(1.46-19.68)$ & 0.012 \\
\hline \multirow[t]{2}{*}{ Dominant } & AA & $118(41.0)$ & $20(29.9)$ & 1.00 (Reference) & & 1.00 (Reference) & \\
\hline & $\mathrm{AG}+\mathrm{GG}$ & $170(59.0)$ & $47(70.1)$ & $1.63(0.92-2.90)$ & 0.095 & $2.50(1.12-5.54)$ & 0.025 \\
\hline \multirow[t]{2}{*}{ Recessive } & $\mathrm{AA}+\mathrm{AG}$ & $260(90.3)$ & $52(77.6)$ & 1.00 (Reference) & & 1.00 (Reference) & \\
\hline & GG & $28(9.7)$ & $15(22.4)$ & $2.68(1.34-5.36)$ & 0.005 & $3.18(1.20-8.42)$ & 0.020 \\
\hline \multirow[t]{2}{*}{ Overdominant } & $\mathrm{AA}+\mathrm{GG}$ & $146(50.7)$ & $35(52.2)$ & 1.00 (Reference) & & 1.00 (Reference) & \\
\hline & $\mathrm{AG}$ & $142(49.3)$ & $32(47.8)$ & $0.94(0.55-1.60)$ & 0.820 & $1.87(0.77-4.52)$ & 0.165 \\
\hline
\end{tabular}

the analysis of adjusted residuals and the logistic regression models, we identified that the AG genotype was associated with mildly to moderately decreased eGFR (G3a), whereas GG genotype was associated with increased risk of kidney failure (G5) as compared with AA genotype, under the codominant model for both outcomes.

These findings are in accordance with a previous Brazilian study that found a higher frequency of the heterozygous genotype (AG) in patients with diabetic nephropathy (DN) than in those with normoalbuminuria in a population of type 2 diabetic patients from the Southeast region [21]. The AG genotype was also associated with urine protein $\geq 3.5 \mathrm{~g} / 24 \mathrm{~h}$ among patients with IgA nephropathy in a Han Chinese population [29]. Moreover, the GG genotype was associated with an increased risk of DN and ESRD in Caucasians from Germany [17]. However, other studies conducted on Tunisian [18], Taiwanese [19], and Turkish [20] patients with type 2 diabetes did not find such an association. Similarly, no association was observed between the $-1082 \mathrm{~A}>\mathrm{G}$ polymorphism and ESRD in white Europeans [30] and Czechs [31]. Conversely, the AA genotype was associated with the increased risk of ESRD in north Indian [32] and Chinese [33] populations. This same genotype was associated with 


\section{Kidney Blood Pressure Research}

nephropathy in Chinese type 2 diabetic patients as compared with subjects without both diabetes and kidney disease [22].

Interleukin-10 plays an important role in the regulation and maintenance of normal renal function, and abnormal IL-10 expression contributes to acute kidney injury and progressive chronic renal failure. In the kidney, IL-10 is mainly expressed in the mesangial and endothelial cells, where it acts as an autocrine cell growth factor [34]. As reviewed by Sinuani et al [34]., IL-10 induces the proliferation of mesangial cells through an increased production of growth factors, cytokines, and chemokines. This leads to structural intraglomerular and tubulointerstitial changes, such as cell hypertrophy, thickening of the glomerular basement membrane, accumulation of mesangial matrix, and overt proteinuria. These pathological changes, in turn, lead to renal failure and ESRD. Considering that the main function of IL10 is to control inflammation $[8,9,34]$, this scenario seems to be a paradox, as the low expression of IL-10 would be expected to be detrimental to renal function due to the loss of anti-inflammatory protection.

In line with this assumption, serum levels of IL-10 were lower in Chinese patients with ESRD as compared with healthy individuals. In addition, the AA genotype was associated with the increased risk of ESRD, and among patients, the serum levels of IL-10 in homozygotes for the $A$ allele of the $-1082 \mathrm{~A}>\mathrm{G}$ polymorphism were lower than in the $\mathrm{G}$ allele carriers [33]. However, the up-regulation of IL-10 has been associated with various kidney diseases [34] and high circulating IL-10 levels were found in diabetic patients $[19,34]$ and in those with macroalbuminuria or chronic kidney disease in type 2 diabetes [10]. In this context, Almeida et al [35]. reported that a session of hemodialysis in type 2 diabetic patients modulates the $\mathrm{T}$ cell activation status and increases the IL-10 serum levels. Evidences from experimental studies show that under certain conditions, IL-10 has protective effects, reducing kidney damage, but in other circumstances, it can worsen the renal function [34].

The identification of specific gene variants that confer predisposition to DKD is complicated mainly by inadequate sample size, heterogeneity in the definition of DKD (which leads to case-control misclassification) [4], and inclusion/exclusion clinical criteria adopted in the association studies [17-22]. Recently, attention has been given to the distinction between DKD defined by albuminuria and DKD defined by eGFR. Albuminuria and the decline of eGFR can develop independently of each other, suggesting that different pathological mechanisms and different gene variants may be involved [4]. In our study, albuminuria levels were not different among patients with $A A, A G$, or GG genotypes, whereas the $-1082 A>G$ polymorphism was associated with eGFR categories. Apart from this, without performing renal biopsy it is not possible to assume that type 2 diabetic subjects with albuminuria or low eGFR have DKD. Renal diseases in type 2 diabetes are more complex and heterogeneous, and a broad range of pathological types of renal diseases can occur in type 2 diabetes $[5,36]$.

Another issue that should be considered is the coexistence of diabetic retinopathy and DKD [37]. We recently found that the $-1082 \mathrm{~A}>\mathrm{G}$ polymorphism is associated with diabetic retinopathy in type 2 diabetic patients (unpublished data). In our population study, $63 \%$ of the patients with kidney failure (eGFR category G5) had proliferative diabetic retinopathy, while only $8 \%$ of the patients with normal or high eGFR (eGFR category G1) did so. Therefore, we cannot rule out the possibility that the association between GG genotype and kidney failure observed in our study is confounded by the occurrence of proliferative diabetic retinopathy. Although our study has the inherent limitations of a case-control study and odds ratios and their confidence intervals are overestimated, our findings suggest that the $-1082 \mathrm{~A}>\mathrm{G}$ polymorphism might be associated with decreased eGFR and should be investigated further.

\section{Conclusion}

In summary, this study showed that the AG genotype was independently associated with increased risk of mildly to moderately decreased eGFR, whereas GG genotype was 


\section{Kidney \\ Blood Pressure Research}

Polina et al.: Association Between -1082A>G Polymorphism and Egfr

independently associated with increased risk of kidney failure as compared with AA genotype. Although these findings are not definitive and need to be replicated in larger studies, taken together, they suggest that the $-1082 \mathrm{~A}>\mathrm{G}$ polymorphism (rs1800896) in the IL10 gene is associated with diabetic kidney disease in type 2 diabetic patients from Southern Brazil.

\section{Disclosure Statement}

The authors declare that they do not have any conflict of interest.

\section{Acknowledgements}

This study was partially supported by research grants from Conselho Nacional de Desenvolvimento Científico e Tecnológico (CNPq), Brasília, Brazil (K.G. Santos is recipient of the scholarship number 303816/2014-7), and Fundo de Incentivo à Pesquisa e Eventos do HCPA (FIPE-HCPA), Porto Alegre, Brazil (grant number 14-0645). The authors thank the government grant agencies for the scholarships/fellowships they provided. E.R. Polina and R.C. Sbruzzi are recipients of scholarships from Coordenação de Aperfeiçoamento de Pessoal de Nível Superior (CAPES) and Fundação de Amparo à Pesquisa do Estado do Rio Grande do Sul (FAPERGS), respectively. D. Crispim and L.H. Canani are recipients of scholarships from CNPq.

\section{References}

1 Lim AKh: Diabetic nephropathy - complications and treatment. Int J Nephrol Renovasc Dis 2014;7:361-381.

$\checkmark 2$ Inker LA, Astor BC, Fox CH, Isakova T, Lash JP, Peralta CA, Kurella Tamura M, Feldman HI: KDOQI US commentary on the $2012 \mathrm{KDIGO}$ clinical practice guideline for the evaluation and management of CKD. Am J Kidney Dis 2014;63:713-735.

-3 Santoro A, Mandreoli M: Chronic renal disease and risk of cardiovascular morbidity-mortality. Kidney Blood Press Res 2014;39:142-146.

4 Ahlqvist E, van Zuydam NR, Groop LC, McCarthy MI: The genetics of diabetic complications. Nat Rev Nephrol 2015;11:277-287.

5 McKnight AJ, Duffy S, Maxwell AP: Genetics of diabetic nephropathy: a long road of discovery. Curr Diab Rep 2015;15:41.

6 Chen NK, Chong TW, Loh HL, Lim KH, Gan VH, Wang M, Kon OL: Negative regulatory responses to metabolically triggered inflammation impair renal epithelial immunity in diabetes mellitus. J Mol Med 2013;91:587-598.

7 Donate-Correa J, Martín-Núñez E, Muros-de-Fuentes M, Mora-Fernández C, Navarro-González JF: Inflammatory cytokines in diabetic nephropathy. J Diabetes Res 2015;2015:948417.

-8 Iyer SS, Cheng G: Role of interleukin 10 transcriptional regulation in inflammation and autoimmune disease. Crit Rev Immunol 2012;32:23-63.

-9 Saxena A, Khosraviani S, Noel S, Mohan D, Donner T, Hamad AR: Interleukin-10 paradox: a potent immunoregulatory cytokine that has been difficult to harness for immunotherapy. Cytokine 2015;74:27-34.

-10 Zhang C, Xiao C, Wang P, Xu W, Zhang A, Li Q, Xu X: The alteration of Th1/Th2/Th17/Treg paradigm in patients with type 2 diabetes mellitus: relationship with diabetic nephropathy. Hum Immunol 2014;75:289-296.

11 Sangoi MB, de Carvalho JA, Tatsch E, Hausen BS, Bollick YS, Londero SW, Duarte T, Scolari R, Duarte MM, Premaor MO, Comim FV, Moretto MB, Moresco RN: Urinary inflammatory cytokines as indicators of kidney damage in type 2 diabetic patients. Clin Chim Acta 2016;460:178-183. 


\section{Kidney \\ Blood Pressure Research}

Polina et al.: Association Between -1082A > G Polymorphism and Egfr

12 Rees LE, Wood NA, Gillespie KM, Lai KN, Gaston K, Mathieson PW: The interleukin-10-1082 G/A polymorphism: allele frequency in different populations and functional significance. Cell Mol Life Sci 2002;59:560-569.

13 Suárez A, Castro P, Alonso R, Mozo L, Gutiérrez C: Interindividual variations in constitutive interleukin-10 messenger RNA and protein levels and their association with genetic polymorphisms. Transplantation 2003;75:711-717.

14 Tarabay M, Elshazli R, Settin A: African vs. Caucasian and Asian difference for the association of interleukin-10 promotor polymorphisms with type 2 diabetes mellitus (a meta-analysis study). Meta Gene 2016;9:10-17.

15 George S, Ruan XZ, Navarrete C, Turner D, Reynard M, Sweny P, Hamilton G, Wheeler DC, Powis SH, Moorhead JF, Varghese Z: Renovascular disease is associated with low producer genotypes of the antiinflammatory cytokine interleukin-10. Tissue Antigens 2004;63:470-475.

16 Stenvinkel P, Pecoits-Filho R, Lindholm B, DialGene Consortium: Gene polymorphism association studies in dialysis: the nutrition-inflammation axis. Semin Dial 2005;18:322-330.

17 Babel N, Gabdrakhmanova L, Hammer MH, Schoenemann C, Skrypnikov V, Poliak N, Volk HD, Reinke P: Predictive value of cytokine gene polymorphisms for the development of end-stage renal disease. J Nephrol 2006;19:802-807.

18 Ezzidi I, Mtiraoui N, Kacem M, Mallat SG, Mohamed MB, Chaieb M, Mahjoub T, Almawi WY: Interleukin-10592C/A, -819C/T and $-1082 \mathrm{~A} / \mathrm{G}$ promoter variants affect the susceptibility to nephropathy in Tunisian type 2 diabetes (T2DM) patients. Clin Endocrinol 2009;70:401-407.

19 Kung WJ, Lin CC, Liu SH, Chaung HC: Association of interleukin-10 polymorphisms with cytokines in type 2 diabetic nephropathy. Diabetes Technol Ther 2010;12:809-813.

-20 Erdogan M, Cetinkalp S, Ozgen AG, Saygili F, Berdeli A, Yilmaz C: Interleukin-10 (-1082G/A) gene polymorphism in patients with type 2 diabetes with and without nephropathy. Genet Test Mol Biomarkers 2012;16:91-94.

21 Rodrigues KF, Pietrani NT, Sandrim VC, Vieira CM, Fernandes AP, Bosco AA, Gomes KB: Association of a large panel of cytokine gene polymorphisms with complications and comorbidities in type 2 diabetes patients. J Diabetes Res 2015;2015:605965.

22 Yin Q, Zhai Q, Wang D, Hai J, Cao M, Wang J, Wang T: Investigation on the association between inerleukin-10 -592C/A, 819C/T and -1082A/G gene polymorphisms and development of diabetic nephrophathy. Int J Clin Exp Pathol 2015;8:15216-15221.

23 American Diabetes Association: Diagnosis and classification of diabetes mellitus. Diabetes Care 2005;28:S37-S42.

24 Colli ML, Gross JL, Canani LH: Mutation H63D in the HFE gene confers risk for the development of type 2 diabetes mellitus but not for chronic complications. J Diabetes Complications 2011;25:25-30.

25 Assmann TS, Lemos NE, Brondani LA, Carlessi R, Maldonado-Bernal C, Cruz M, Canani LH, Crispim D: Association between Asp299Gly and Thr399lle polymorphisms in toll-like receptor 4 gene and type 2 diabetes mellitus: case-control study and meta-analysis. J Diabetes Metab DOI: 10.4172/21556156.1000449.

-26 Levey AS, Stevens LA, Schmid CH, Zhang YL, Castro AF 3rd, Feldman HI, Kusek JW, Eggers P, Van Lente F, Greene T, Coresh J, CKD-EPI (Chronic Kidney Disease Epidemiology Collaboration): A new equation to estimate glomerular filtration rate. Ann Intern Med 2009;150:604-612.

27 Lahiri DK, Nurnberger JI: A rapid non-enzymatic method for the preparation of HMW DNA from blood for RFLP studies. Nucleic Acids Res 1991;19:5444.

28 Abramson JH: WINPEPI updated: computer programs for epidemiologists, and their teaching potential. Epidemiol Perspect Innov 2011;8:1.

29 Gao J, Wei L, Fu R, Wei J, Niu D, Wang L, Ge H, Yu Q, Wang M, Liu X, Zhang W: Association of interleukin-10 polymorphisms (rs1800872, rs1800871, and rs1800896) with predisposition to IgA nephropathy in a Chinese Han population: a case-control study. Kidney Blood Press Res 2017;42:89-98.

-30 Buckham TA, McKnight AJ, Benevente D, Courtney AE, Patterson CC, Simmonds M, Gough S, Middleton D, Borrows R, Maxwell AP: Evaluation of five interleukin genes for association with end-stage renal disease in white Europeans. Am J Nephrol 2010;32:103-108. 


\section{Kidney \\ Blood Pressure Research}

Polina et al.: Association Between -1082A>G Polymorphism and Egfr

-31 Bloudíčková S, Kuthanová L, Hubáček JA: Polymorphisms in IFN- $\gamma$, TNF- $\alpha$ and IL-10 in patients on maintenance haemodialysis. Folia Biol 2011;57:30-34.

-32 Manchanda PK, Singh R, Mittal RD: Cytokine (IL-10 -1082 and -819) and chemokine receptor (CCR2 and CCR5) gene polymorphism in North Indian patients with end-stage renal disease. DNA Cell Biol 2009;28:177-183.

-33 Wu HC, Ling H, Na SP, Xie RJ: [The research on the relationship between the polymorphism of 1082A/G, anti-inflammatory interleukin-10 gene promoter with its effect of preventing ESRD patients from microinflammation and arteriosclerosis]. Zhonghua Yi Xue Za Zhi 2005;85:2076-2080.

-34 Sinuani I, Beberashvili I, Averbukh Z, Sandbank J: Role of IL-10 in the progression of kidney disease. World J Transplant 2013;3:91-98.

35 Almeida A, Lourenço 0, Fonseca AM: Haemodialysis in diabetic patients modulates inflammatory cytokine profile and T cell activation status. Scand J Immunol 2015;82:135-141.

36 Dong Z, Wang Y, Qiu Q, Zhang X, Zhang L, Wu J, Wei R, Zhu H, Cai G, Sun X, Chen X: Clinical predictors differentiating non-diabetic renal diseases from diabetic nephropathy in a large population of type 2 diabetes patients. Diabetes Res Clin Pract 2016;121:112-118.

-37 Hung CC, Lin HY, Hwang DY, Kuo IC, Chiu YW, Lim LM, Hwang SJ, Chen HC: Diabetic retinopathy and clinical parameters favoring the presence of diabetic nephropathy could predict renal outcome in patients with diabetic kidney disease. Sci Rep 2017;7:1236. 